\title{
Fenologia reprodutiva do maracujazeiro-azedo no município de Campos dos Goytacazes, RJ
}

\author{
Reproductive phenological of passion fruit in Campos dos Goytacazes, RJ, Brazil
}

\author{
Sérgio Alessandro Machado Souza ${ }^{\mathrm{I}}$ Kellen Coutinho Martins ${ }^{\mathrm{I}}$ Amanda Silva de Azevedo ${ }^{\mathrm{I}}$ \\ Telma Nair Santana Pereira ${ }^{\mathrm{I}^{*}}$
}

\section{RESUMO}

Este estudo teve como objetivo caracterizar a fenologia reprodutiva do maracujazeiro-azedo no período de setembro de 2009 a setembro de 2010, nas condições do

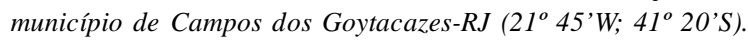
Avaliaram-se os dados referentes ao florescimento e frutificação, correlacionados com variáveis climatológicas (temperatura e pluviosidade). Uma escala para a avaliação do desenvolvimento dos estádios fenológicos reprodutivos do maracujazeiro-azedo foi proposta, com base em imagens digitalizadas de nove fenofases. Observou-se que o florescimento foi de outubro a março, meses com as maiores temperaturas médias, com pico no mês de janeiro e maior percentagem de frutos maduros no mês de fevereiro. A escala das diferentes fenofases foi útil na caracterização da fenologia reprodutiva do maracujazeiroazedo. A variável temperatura apresentou alta correlação com o número de flores $(0,87)$, indicando que é um agente fundamental no florescimento do maracujazeiro-azedo.

Palavras-chave: temperatura, florescimento, frutificação, análise de trilha.

\section{ABSTRACT}

This research aimed to characterize the reproductive phenological of sour passion fruit from September 2009 to September 2010, in Campos dos Goytacazes city, Rio de Janeiro state, Brazil (21 $\left.45^{\prime} W ; 41^{\circ} 20^{\prime} S\right)$. Data of flowering and fructification were evaluated and correlated with climatologic variables (temperature and rainfall). To evaluate phenological stages a scale was proposed based on digitals images of nine reproductive stages. The scale was useful in passion fruit reproductive phenological characterization. The flowering was of October to March, peak in January, and the peak fructification in February. The temperature showed high correlation with number of flowers (0.87), thus indicating that the temperature has an important effect in flowering of sour passion fruit.

Key words: temperature, flowering, fructification, path analyze.

\section{INTRODUÇÃO}

O gênero Passiflora é amplamente distribuído pelas Américas e possui uma grande variabilidade genética a ser explorada nos programas de melhoramento, cuja avaliação e caracterização são ferramentas indispensáveis na ampliação desses estudos (GANGA et al., 2004). O interesse econômico pelas espécies do gênero Passiflora deve-se principalmente à produção de frutos, com destaque para o maracujá-azedo (Passiflora edulis Sims), que é a espécie mais cultivada e predominante no mercado (OLIVEIRA et al., 2008). Mesmo com a grande importância econômica da espécie, a maioria dos estudos relacionados à geração de informações básicas para os programas de melhoramento genético são recentes (VIANA et al., 2006), e estudos relacionados à fenologia da cultura ainda são incipientes.

Segundo GASPARI-PEZZOPANE et al. (2009), o conhecimento do comportamento de espécies cultivadas em relação ao ciclo fenológico, como

'Laboratório de Melhoramento Genético Vegetal (LMGV), Universidade Estadual do Norte Fluminense Darcy Ribeiro (UENF), 28013-602, Campos dos Goytacazes, RJ, Brasil. E-mail: telmasp@uenf.br. *Autor para correspondência. 
uniformidade de maturação, duração do ciclo e florescimento, é essencial para subsidiar pesquisas visando ao melhoramento genético. Na concepção de LAWINSCKI (2010), em experimentos envolvendo hibridação interespecífica, as informações referentes à fenologia são imprescindíveis, pois auxiliam na escolha de genitores cujo florescimento seja sincronizado. Em $\boldsymbol{P}$. edulis, as fases de floração e frutificação sofrem grande influência do ambiente (CAMILO, 2003), sendo, de suma importância, realizar pesquisas em períodos e locais a fim de caracterizar os estádios fenológicos dessa espécie.

Devido à grande importância econômica do maracujazeiro-azedo, este estudo teve como objetivo, realizar a caracterização da fenologia reprodutiva, elaborar uma escala ao atribuir notas a cada estádio fenológico reprodutivo e avaliar os atributos: taxa e pico de florescimento, além da taxa de frutificação.

\section{MATERIAL E MÉTODOS}

O estudo foi realizado no município de Campos dos Goytacazes, região norte do estado do Rio de Janeiro, na unidade de apoio a pesquisa da Escola Agrícola Antônio Sarlo, localizada a $21^{\circ} 45^{\prime} \mathrm{de}$ latitude sul e $41^{\circ} 20^{\prime}$ de longitude oeste e situada a $11 \mathrm{~m}$ de altitude, durante o período de setembro de 2009 a setembro de 2010. O experimento foi conduzido em delineamento em blocos ao acaso, com 10 plantas na parcela, com idade aproximada de 10 meses, arranjado em cinco blocos, totalizando 50 plantas, dispostas no sistema de espaldeiras verticais com um fio de arame situado a $1,75 \mathrm{~m}$ do solo, no espaçamento de $2 \mathrm{~m}$ entre plantas e 2,5m entre linhas, segundo BRUCKNER \& PICANÇO(2001).

O clima da região é classificado por Köppen como tropical-quente, com inverno seco e verão quente e chuvoso. Para a caracterização das condições meteorológicas ocorridas durante o período experimental, foram obtidos os dados climatológicos (pluviosidade e temperatura) a partir da estação convencional do INMET - Instituto Nacional de Meteorologia - situada no local do presente estudo.

Para a elaboração da escala das fases fenológicas, foi marcada, em todas as plantas, uma ramificação, assim que observado o surgimento da gema floral e registrado o dia da ocorrência do evento fenológico, bem como as posteriores mudanças de estádios. As marcações sempre ocorreram no primeiro dia de cada mês, com exceção do mês de outubro, no qual o surgimento da gema floral ocorreu no $10^{\circ}$ dia. Para a elaboração da escala de notas, foram obtidas fotografias digitais com a finalidade de identificar nove estádios reprodutivos do maracujazeiro-azedo, sendo esses de fácil identificação e que apresentassem alterações morfológicas significativas durante a fenologia reprodutiva da espécie. A duração do ciclo reprodutivo foi calculada a partir das datas fornecidas de cada nota fenológica, sendo contados os dias desde o surgimento da gema floral até o amadurecimento completo do fruto, e esses dados comparados com os meses de avaliação, temperatura e pluviosidade.

O número de flores, quando presente, foi registrado diariamente em todas as plantas e, com base nesses dados, foram estimados a taxa de florescimento (razão entre o número total de flores na antese e o número de dias analisados) e o pico de florescimento, ou seja, o maior número de flores na antese em um único dia. Além das avaliações fenológicas relacionadas à floração, foi realizada, em conjunto, a determinação da taxa de frutificação (razão entre o número total de frutos completamente maduros e o número de dias analisados).

Os dados das avaliações fenológicas referentes à floração (taxa de florescimento e pico de florescimento) e frutificação (taxa de frutificação) foram submetidos à estatística descritiva, utilizando-se medidas de tendência central e de variabilidade de dados; as variáveis (número de flores, número de frutos, temperatura e pluviosidade) foram analisadas via correlação, desdobrados em efeitos diretos e indiretos, com a finalidade de verificar os efeitos diretos e indiretos das variáveis climatológicas sobre as fenológicas. As análises foram realizadas com o auxílio do programa GENES (CRUZ, 2006).

\section{RESULTADOS E DISCUSSÃO}

As imagens digitalizadas que compõem a escala de notas para avaliar os estádios fenológicos do maracujazeiro-azedo estão representadas na figura 1 . As notas atribuídas e os eventos fenológicos corresponderam, respectivamente a: (0) surgimento da gema floral, (1) desenvolvimento do botão floral, (2) botão floral desenvolvido, (3) botão floral dois dias antes da antese, (4) botão floral no dia da antese, (5) antese, (6) desenvolvimento inicial do fruto, (7) desenvolvimento final do fruto e (8) fruto maduro. De 


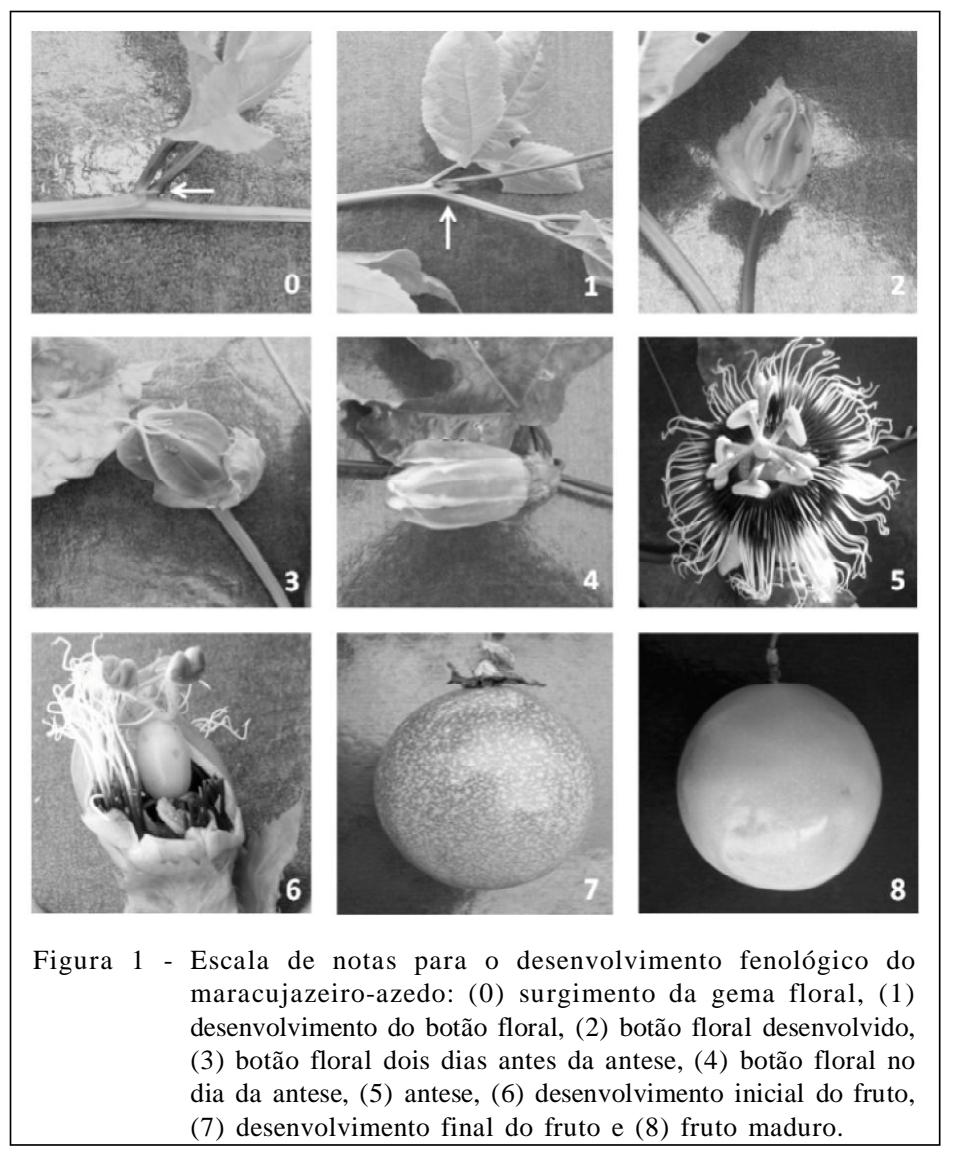

acordo com PEZZOPANE et al. (2003), é de suma importância atribuir uma escala de notas aos estádios fenológicos de uma determinada cultura, pois, durante a sucessão das fases vegetativas e reprodutivas, as plantas passam por estádios fenológicos que determinam etapas importantes do desenvolvimento e, sendo bem caracterizados, podem auxiliar pesquisas relacionadas a estimativas de cultivo, previsão da época de maturação e programas de melhoramento genético.

Os atributos fenológicos utilizados estão relacionados à importância destes nas pesquisas com o maracujazeiro-azedo. Os três primeiros atributos são fundamentais, em estudos sobre o comportamento meiótico, pois a microsporogênese e a microgametogênese estão associadas ao tamanho do botão floral (SOUZA et al., 2002). A análise do botão floral dois dias antes da antese é de grande importância em estudos de autoincompatibilidade, pois essa reação, do tipo esporofítica presente no maracujazeiro-azedo, está relacionada diretamente à idade do estigma da flor, pois, polinizações realizadas dois dias antes da antese, utilizando polens maduros e incompatíveis, resultaram em fertilização da oosfera (MADUREIRA, 2009). O botão floral, no dia da antese, é empregado em estudos de caracterização palinológica (MILWARD-DEAZEVEDO et al., 2004) e de viabilidade polínica (SOUZA et al., 2002). O estádio de antese e do desenvolvimento inicial dos frutos são importantes em experimentos de hibridação e na avaliação da taxa de pegamento de frutos (MELETTI et al., 2000). Por sua vez, as duas últimas fenofases são importantes devido ao fato de o interesse econômico pela cultura estar relacionado principalmente à produção de frutos (OLIVEIRA et al., 2008).

Durante o período analisado, o maracujazeiroazedo apresentou desenvolvimento de gema floral e florescimento entre os meses de outubro de 2009 a março de 2010 , tendo-se a maior temperatura média, em $32^{\circ} \mathrm{Ce}$ pluviosidade variando de $20 \mathrm{~mm}$ (fevereiro de 2010) a $125 \mathrm{~mm}$ (dezembro de 2009) (Figura 2). De acordo com BENEVIDES et al. (2009), ao analisarem diferentes localidades da região norte fluminense, incluindo a do 


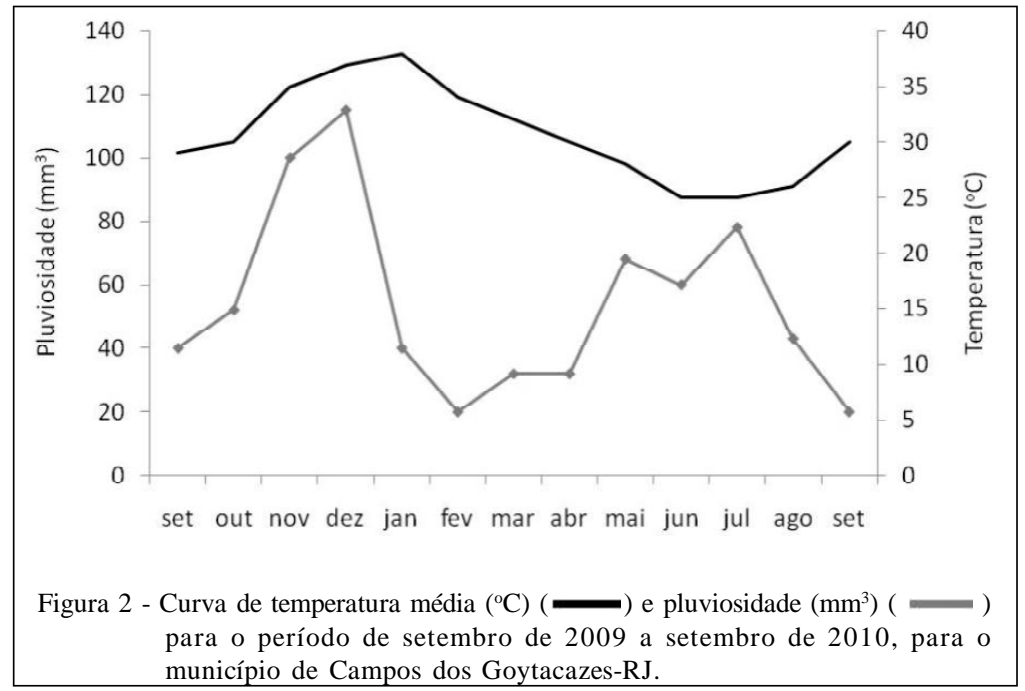

presente estudo, entre outubro de 2004 e setembro de 2005, foi observado florescimento de setembro a junho, abrangendo o período de maior temperatura média, sendo, entretanto, observadas variações significativas, entre cinco e noves meses, nos períodos de florescimento. Esses dados evidenciam a importância de uma caracterização fenológica contínua da espécie na região do presente estudo, pois esses resultados poderão auxiliar na adoção de práticas culturais eficientes, visando, por exemplo, ao aumento da produtividade na região.

Do surgimento da gema floral até o amadurecimento completo do fruto, os meses de outubro, novembro, dezembro, janeiro, fevereiro e março apresentaram, em média, respectivamente, 43, 43, 41, 40, 39 e 59 dias de ciclo fenológico reprodutivo (Figura 3), com média de 44 dias durante o período supracitado. O maracujazeiro-azedo apresentou um menor ciclo fenológico reprodutivo quando a temperatura média do período foi mais elevada (Figura 2). Segundo SILVA et al. (2005), o maracujazeiro-azedo, no local do presente estudo, apresentou, em média, 57 dias do surgimento do botão floral ao amadurecimento completo do fruto, porém os mesmos autores não relatam as condições climáticas da sua pesquisa.

$\mathrm{Na}$ concepção de FORSTHOFER et al. (2004), o ciclo fenológico pode variar em diferentes períodos dentro de um mesmo ano, pois a radiação solar, temperatura, pluviosidade e umidade relativa do ar são fatores limitantes no desenvolvimento fenológico de uma determinada espécie.
O pico de florescimento foi de oito flores, no mês de janeiro, e a maior incidência de frutos maduros foi contabilizada no mês de fevereiro, com taxa de frutificação de 3,57 (Tabela 1). O maracujazeiroazedo é uma espécie exigente quanto à luminosidade, necessitando aproximadamente de 12 horas diárias de luz para florescer, justificando, dessa forma, seu pico de florescimento em períodos do ano com dias mais longos (CAMILO, 2003).

A partir da análise de correlação, foi possível verificar o efeito dos fatores ambientais sobre o ciclo fenológico reprodutivo do maracujazeiro-azedo. Pela decomposição do coeficiente de correlação em efeitos diretos e indiretos (Tabela 2), observou-se forte associação entre a temperatura e o número de flores, cujos coeficientes de correlação $(0,87)$ e de efeito direto $(0,78)$ apresentaram valores similares. A temperatura apresentou correlação expressiva $(0,66)$ com o amadurecimento dos frutos, indicando que essa variável possui influência significativa sobre essa fenofase.

De acordo com VENCOVSKY \& BARRIGA (1992), quando o coeficiente de correlação e o efeito direto forem semelhantes, em magnitude e sinal, essa correlação direta explica a verdadeira associação entre as variáveis. Isso representa que, aparentemente, essa variável (temperatura) atua com maior independência e influencia diretamente no número de flores e no amadurecimento dos frutos durante o ciclo fenológico reprodutivo do maracujazeiro-azedo. Dessa forma, ao obter as correlações e decompô-las em efeitos diretos

Ciência Rural, v.42, n.10, out, 2012. 


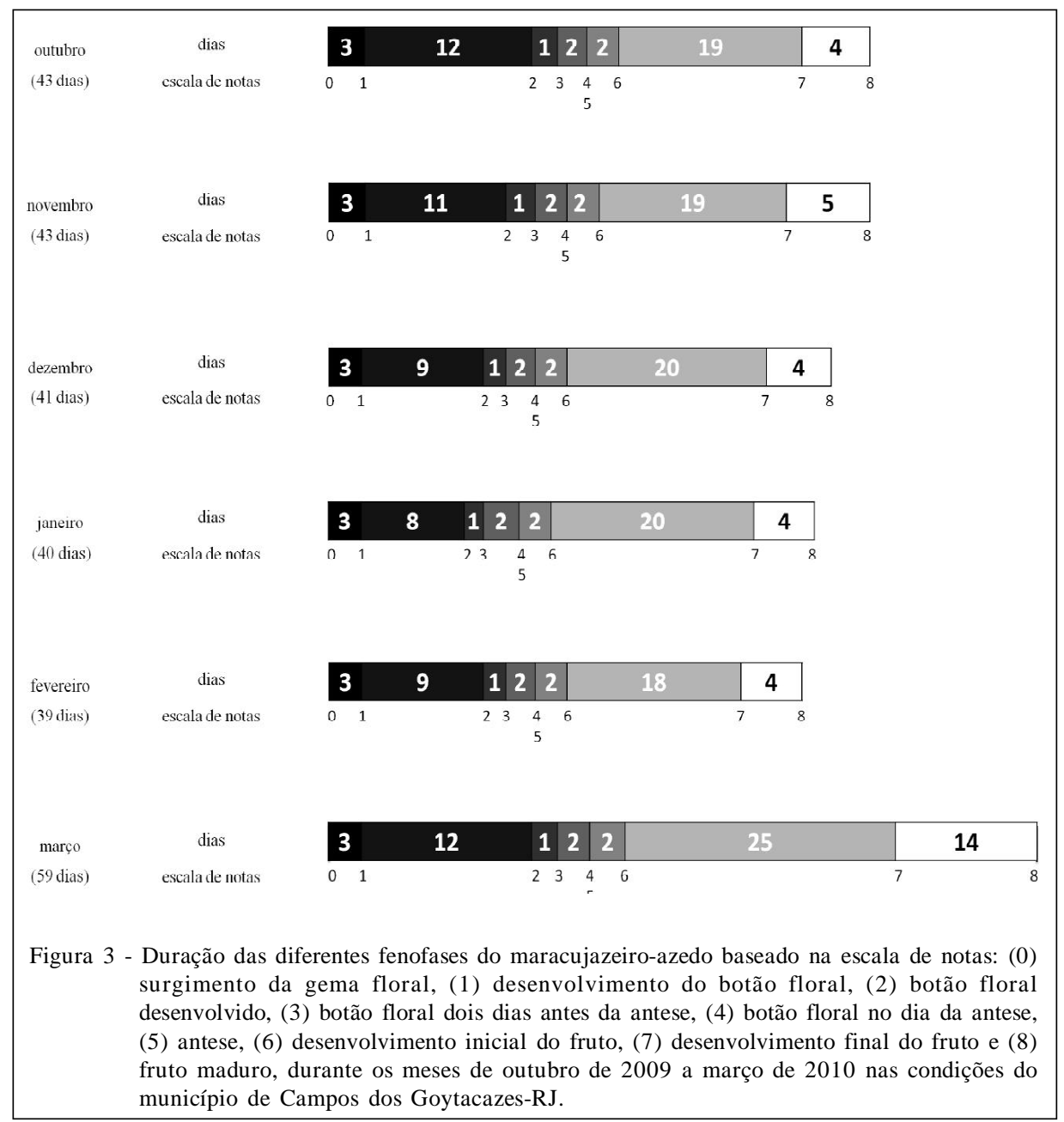

e indiretos, é possível obter dados mais acurados sobre o verdadeiro efeito de uma variável sobre uma determinada característica, sendo essa análise uma importante ferramenta na caracterização do ciclo fenológico de uma determinada espécie.

\section{CONCLUSÃO}

Nas condições experimentais deste estudo, a duração do ciclo fenológico reprodutivo variou com o mês de avaliação, assim como o desenvolvimento

Tabela 1 - Taxa de florescimento, pico de florescimento e taxa de frutificação durante a caracterização do ciclo fenológico reprodutivo do maracujazeiro-azedo, nas condições do município de Campos dos Goytacazes-RJ, de outubro de 2009 a março de 2010.

\begin{tabular}{lccc}
\hline Mês & Taxa de florescimento & Pico de florescimento & Taxa de frutificação \\
\hline outubro & 1,38 & 4,00 & - \\
novembro & 1,66 & 4,00 & 1,26 \\
dezembro & 2,03 & 6,00 & 1,45 \\
janeiro & 3,85 & 8,00 & 1,87 \\
fevereiro & 3,61 & 7,00 & 3,57 \\
março & 2,93 & 5,00 & 3,22 \\
desvio padrão médio & 0,94 & 1,48 & 0,88 \\
CV (\%) & 15,79 & 26,14 & 41,40 \\
\hline
\end{tabular}


Tabela 2 - Estimativa dos efeitos diretos e indiretos e correlação entre a variável número de flores, número de frutos, amadurecimento dos frutos, temperatura e pluviosidade durante a caracterização do ciclo fenológico reprodutivo do maracujazeiro-azedo, nas condições do município de Campos dos Goytacazes-RJ.

\begin{tabular}{llc}
\hline Vias de associação & Temperatura & 0,12 \\
& & \\
Efeito direto sobre o número de flores & 0,78 \\
Efeito indireto no número de flores via temperatura & - & 0,15 \\
Efeito indireto no número de flores via pluviosidade & 0,09 & 0, \\
Total (Correlação) & $0,87^{* *}$ & $0,27^{\mathrm{ns}}$ \\
Efeito direto sobre o número de frutos & 0,20 & 0,14 \\
Efeito indireto no número de frutos via temperatura & - & 0,03 \\
Efeito indireto no número de frutos via pluviosidade & 0,02 & - \\
Total (Correlação) & $0,22^{\mathrm{ns}}$ & $0,17^{\mathrm{ns}}$ \\
Efeito direto sobre o amadurecimento dos frutos & 0,59 & 0,05 \\
Efeito indireto sobre o amadurecimento dos frutos via temperatura & - & 0,09 \\
Efeito indireto sobre o amadurecimento dos frutos via pluviosidade & 0,07 & - \\
Total (Correlação) & $0,66^{*}$ & $0,14^{\mathrm{ns}}$ \\
\hline
\end{tabular}

$\mathrm{ns}, * * \mathrm{e} *$. Não significativo, significativo 1 e $5 \%$ de probabilidade, respectivamente, pelo teste $\mathrm{F}$.

fenológico e dias para a maturação dos frutos. Esse fato indica que a fenologia reprodutiva do maracujazeiro-azedo apresenta alta influência de fatores ambientais, como, por exemplo, a temperatura.

\section{AGRADECIMENTOS}

À Fundação Carlos Chagas Filho de Amparo a Pesquisa do Estado do Rio de Janeiro (FAPERJ), pelo suporte financeiro e pela concessão da bolsa de doutorado ao primeiro autor.

\section{REFERÊNCIAS}

BENEVIDES, C.R. et al. Visitantes florais do maracujá-amarelo (Passiflora edulis f. flavicarpa Deg. Passifloraceae) em áreas de cultivo com diferentes proximidades a fragmentos florestais na região Norte Fluminense, RJ. Revista Brasileira de Entomologia, v.53, p.415-421, 2009. Disponível em: <http:/ /www.scielo.br/pdf/rbent/v53n3/16.pdf>. Acesso em: 10 out. 2010. doi: 10.1590/S0085-56262009000300016.

BRUCKNER, C.R.; PICANÇO, M.C. Maracujá: tecnologia de produção, pós-colheita, agroindústria e mercado. Porto Alegre: Cinco Continentes, 2001. 472p.

CAMILO, E. Polinização do maracujá. Ribeirão Preto: Holos, 2003. 44p.

CRUZ, C.D. Programa GENES: análise multivariada e simulação. Viçosa: UFV, 2006. 175p.

FORSTHOFER, E.L. et al. Desenvolvimento fenológico e agronômico de três híbridos de milho em três épocas de semeadura. Ciência Rural, v.34, p.1341-1348, 2004 Disponível em: <http://www.scielo.br/pdf/cr/v34n5/ a04v34n5.pdf>. Acesso em: 15 out. 2009. doi: 10.1590/S010384782004000500004 .
GANGA, R.M.D. et al. Diversidade genética em maracujazeiroamarelo utilizando marcadores moleculares fAFLP. Revista Brasileira de Fruticultura, v.26, p.494-498, 2004. Disponível em: 〈http://www.scielo.br/pdf/rbf/v26n3/23153.pdf〉. Acesso em: 20 nov. 2010. doi: 10.1590/S0100-294 52004000300029.

GASPARI-PEZZOPANE, C. et al. Atributos fenológicos e agronômicos em cultivares de cafeeiro arábica. Ciência Rural, v.39, p.711-717, 2009. Disponível em: <http://www.scielo.br/ pdf/cr/v39n3/a113cr291.pdf $>$. Acesso em: 5 jan. 2010. doi: 10.1590/S0103-84782009005000007.

LAWINSCKI P.R. Caracterização morfológica, reprodutiva e fenológica de Passiflora alata CURTIS e Passiflora cincinata MAST. 2010. 134f. Dissertação (Mestrado em Produção Vegetal) - Curso de Pós-graduação em Produção Vegetal, Universidade Estadual de Santa Cruz.

MELETTI, L.M.M. et al. Melhoramento do maracujazeiroazedo: obtenção do cultivar 'composto IAC-27'. Scientia Agrícola, v.57, p.491-498, 2000. Disponível em: <http:// www.scielo.br/pdf/sa/v57n3/2681.pdf>. Acesso em: 20 abr. 2010. doi: 10.1590/S0103-90162000000300019.

MADUREIRA, H.C. Caracterização celular e molecular do sistema de auto-incompatibilidade esporofítica do maracujazeiro-amarelo (Passiflora edulis Sims). 2009. 81f. Tese (Doutorado em Genética e Melhoramento de Plantas) - Curso de Pós-graduação em Genética e Melhoramento de Plantas, Universidade Estadual do Norte Fluminense Darcy Ribeiro, RJ.

MILWARD-DE-AZEVEDO, M.A. et al. Palinotaxonomia das espécies de Passiflora L. subg. Decaloba (DC.) Rchb. (Passifloraceae) no Sudeste do Brasil. Revista Brasileira de Botânica, v.27, p.655-665, 2004. Disponível em: <http:// www.scielo.br/pdf/rbb/v27n4/v27n4a06.pdf>. Acesso em: 8 set. 2009. doi: $10.1590 / \mathrm{S} 0100-84042004000400006$. 
OLIVEIRA, E.J. et al. Seleção em progênies de maracujazeiroamarelo com base em índices multivariados. Pesquisa Agropecuária Brasileira, v.43, p.1543-1549, 2008. Disponível em: 〈http://www.scielo.br/pdf/pab/v43n11/13.pdf>. Acesso em: 12 fev. 2011. doi: 10.1590/S0100-204X2008001100014.

PEZZOPANE, J.R.M. et al. Escala de avaliação de estádios fenológicos do cafeeiro arábica. Bragantia, v.62, p.499-505, 2003. Disponível em: <http://www.scielo.br/pdf/brag/v62n3/ v62n3a15.pdf>. Acesso em: 2 set. 2009. doi: 10.1590/S000687052003000300015 .

SOUZA, M.M. et al. Microsporogênese e microgametogênese associadas ao tamanho do botão floral e da antera e viabilidade polínica em maracujazeiro-amarelo (Passiflora edulis Sims f. flavicarpa Degener). Ciência e Agrotecnologia, v.26, p.12091217, 2002. Disponível em: <http://www.editora.ufla.br/site/ _adm/upload/revista/26-6-2002_13.pdf>. Acesso em: 7 jun. 2008.
SILVA, T.V. et al. Influência dos estádios de maturação na qualidade do suco do maracujá-amarelo. Revista Brasileira de Fruticultura, v.27, p.472-475, 2005. Disponível em: <http://www.scielo.br/pdf/rbf/v27n3/27799.pdf>. Acesso em: 27 abr. 2012.

VENCOVSKY, R.; BARRIGA, P. Genética biométrica no fitomelhoramento. Ribeirão Preto: SBG, 1992. 496p.

VIANA, A.P. et al. Diversidade genética entre genótipos comerciais de maracujazeiro amarelo (Passiflora edulis f. flavicarpa) e entre espécies de passifloras nativas determinada por marcadores RAPD. Revista Brasileira de Fruticultura, v.25, p.489-493, 2006. Disponível em: <http://www.scielo.br/ pdf/rbf/v25n3/18675.pdf>. Acesso em: 08 jul. 2009. doi: 10.1590/S0100-29452003000300032. 